\title{
Hereditary thrombophilia due to congenital histidine-rich (poly-L) glycoprotein deficiency
}

INSERM

\section{Source}

INSERM. (1999). Orphanet: an online rare disease and orphan drug data base. Hereditary thrombophilia due to congenital histidine-rich (poly-L) glycoprotein deficiency. ORPHA:217467

Hereditary thrombophilia due to congenital histidine-rich (poly-L) glycoprotein deficiency is a rare, genetic, coagulation disorder characterized by a tendency to develop thrombosis, resulting from decreased histidine-rich glycoprotein (HRG) plasma levels. Manifestations are variable depending on location of thrombosis, but may include headaches, diplopia, prog ressive pain, limb swelling, itching or ulceration, and brownish skin discoloration, among others. 